\title{
Hak untuk memperoleh pelayanan kesehatan jiwa
}

\author{
Nine Wahyu Agustina \\ IIK STRADA INDONESIA \\ Ninewahyu7@gmail.com
}

\begin{abstract}
ABSTRAK
kesehatan jiwa merupakan kondisi dimana seorang individu dapat berkembang secara fisk,mental,spiritual,dan social sehingga individu tersebut menyadari kemampuan sendiri ,dapat mengatasi tekanan,dan dapat bekerja secara produktif ,dan mampu memberikan konstribusi untuk komunitasnya.semua orang berhak mendapatkan informasi tentang kesehatan .dengan demikian,masyarakat akan mengetahui dengan jelas semua hal tentang kesehatan khususnya kesehatan jiwa.kesehatan jiwa menentukan kemampuan hidup manusia untuk produktif secara social dan ekonomi .kesehatan jiwa menjamin setiap orang dapat menikmati kehidupan kejiwaan yang sehat,bebas dari ketakutan ,tekanan,dan gangguan lain yang dapat menganggu.
\end{abstract}

Kata Kunci: pelayanan kesehatan ,kesehatan jiwa ,perlindungan hak

\section{Latar belakang}

Kesehatan jiwa merupakan salah satu hal penting yang dibutuhkan manusia dalam menjalankan segala aspek kehidupan baik dalam lingkup keluarga maupun bermasyarakat karena dalam jiwa yang sehat maka jasmani dan rohani manusia dapat menjadikan diri menjadi manusia bernilai,berakal,berahlaq,berguna dalam kehidupan ,sejahtera dan bermartabat .sehingga kesehatan kejiwaan menjadi hal yang sangat penting dalam berfikir jernih dan rasional bagi manusia ,sangat disayangkan jika kesehatan kejiwaan manusia terganggu karena tidak bisa berfikir jernih ,selalu berhalusinasi,ketakutan dan emosi tak terkontrol dan tidak bisa menjalankan kehidupan sosialnya secara normal penyebanya seperti factor dikriminasi dan prasangka ,prasangka juga mempunyai berbagai bentuk dan jenis diantaranya adalah :seksisme(sexime),prasangka social,agisme,sedangkan dikriminisasi memiliki jenis jenisnya yaitu: diskriminasi berdasarkan suku,etnis,ras dan agama.diskriminasi berdasarkan jenis kelamin dan gender.

Kelurahan Wonokromo memiliki pelayanan kesehatan jiwa melalui kader kesehatan 
(karsewa) . hal ini merupakan upaya masyarakat dalam meningkatkan kesadaran kesehatan jiwa di kelurahan wonokromo melalui 5 program pokok karsewa sejak satu tahun terakhir. Namun, kesadaran masyarakat khususnya keluarga dengan ODGJ (orang dengan gangguan jiwa ) untuk berkunjung dan berperan aktif dalam kegiatan posyandu jiwa masih kurang.hasil kunjungan masyarakat pada posyandu jiwa bulan pertama sebanyak 10 pasien,bulan kedua sebanyak 12 pasien serta bulan ketiga sebanyak 11 pasien. Hal ini menunjukkan masih rendahnya minat dan keikutsertakaan masyarakat dalam kegiatan posyandu jiwa.

Metode : penelitian ini deskriptif dengan tujuan mengindentifikasi peran keluarga dan masyarakat terhadap karsewa sebagai tempat pelayanan pertama kesehatan jiwa di kelurahan wonokromo. Hasil penelitian ini: dari 99 kasus disabilitas (termasuk gangguan jiwa) dari 42.620 penduduk .setelah dilakukan program pelayanan oleh karsewa wonokromo, di dadapatkan data 52 orang menderita gangguan jiwa, artinya kesadaran keluarga terhadap pengobatan ODGJ semakin meningkat demikian juga peran serta masyarakat dalam mengikuti program pokok karsewa.dapat disimpulkan bahwa karsewa merupakan satu upaya manajemen pelayanan kesehatan jiwa berbasis masyarkat,perlu digerakkan secara berkesinambungan guna meningkatkan kesadaran dan pemberdayaan masyarkat secara mandiri dalam hal promotif,preventif dan rehabilitatif.

\section{Kasus/masalah}

Dari Latar Belakang yang dapat dirumuskan Masalah-Masalah Sebagai Berikut:

kesadaran masyarakat khususnya keluarga dengan ODGJ (orang dengan gangguan jiwa ) untuk berkunjung dan berperan aktif dalam kegiatan posyandu jiwa masih kurang.hasil kunjungan masyarakat pada posyandu jiwa bulan pertama sebanyak 10 pasien,bulan kedua sebanyak 12 pasien serta bulan ketiga sebanyak 11 pasien. Hal ini menunjukkan masih rendahnya minat dan keikutsertakaan masyarakat dalam kegiatan posyandu jiwa.

\section{Tinjaun pustaka}

Kesehatan merupakan modal utama bagi pertumbuhan dan kehidupan bangsa,dan mempunyai peran penting dalam rangka mewujudkan masyarakat adil makmur dan sejahtera seperti cita-cita bernegara yang tercantum dalam pembukaan UUD 1945.derajat kesehatan juga sangat berarti bagi pengembangan dan pembinaan sumber daya manusia yang merupakan modal dasar pembangunan nasional yang pada hakekatnya adalah pembangunan manusia seutuhnya.untuk mencapai derajat kesehatan masyarakat yang baik ,sebagai bagian dari hak asasi manusia (warga Negara),maka Negara wajib memenuhi hak ,atas pelayanan kesehatan ini,mencoba menurut konstitusionalisme ha katas pelayanan kesehatan di Indonesia dengan melihat pengaturannya dalam berbagai peraturan perundang-undangan dan bagaimana penyelenggraannya.

Pelayanan kesahatan merupakan kebutuhan primer dalam kehidupan setiap manusia, dan merupakan hak untuk mendapatkannya, maka setiap orang membutuhkan kondisi badan 
yang sehat agar mampu menjalankan aktifitas sehari-hari guna mencapai hidup yang sejahtera. Selain hal tersebut, kesehatan merupakan Hak Azasi Manusia dan salah satu unsur kesejahteraan masyarakat yang harus diwujudkan sesuai dengan cita-cita bangsa Indonesia, sebagaimana dimaksud dalam Pancasila dan UUD Tahun 1945. Selanjutnya bahwa setiap kegiatan dalam upaya untuk memelihara dan meningkatkan derajat kesehatan masyarakat yang setinggi-tingginya, dilaksanakan berdasarkan prinsip nondiskriminasi, partisipatif dan berkelanjutan dalam rangka untuk membentuk sumber daya manusia Indonesia, serta meningkatkan ketahanan dan daya saing bangsa bagi pembangunan nasional. Dalam setiap hal yang menyebabkan terjadinya gangguan kesehatan pada masyarakat Indonesia, akan menimbulkan kerugian ekonomi yang besar bagi negara, dan setiap upaya untuk meningkatkan derajat kesehatan masyarakat juga berarti merupakan investasi bagi pembangunan negara. Oleh sebab itu, setiap upaya pembangunan harus dilandasi dengan wawasan kesehatan dalam artian pembangunan nasional harus memperhatikan kesehatan bagi masyarakat dan tentu saja harus merupakan tanggung jawab semua pihak baik bagi Pemerintah, maupun bagi masyarakat.

Kesehatan jiwa menurut WHO (world Health organization) adalah ketika seseorang tersebut merasa sehat dan bahagia ,mampu menghadapi tantangan hidup serta dapat menerima orang lain sebagaimana seharusnya serta mempunyai sikap positif terhadap diri sendiri dan orang lain.kondisi sikap yang negative atau tidak sesuai pada individu disebut gangguan jiwa (UU No.18 tahun 2014)gangguan jiwa adalah sindrom atau pola psikologis atau pola periaku yang penting secara klinis yang terjadi pada individu dan sindrom ini dihubungkan dengan adanya distress atau disabilitas, data statistik yang dikemukakan oleh WHO 2012 menyebutkan bahwa sekitar 450 juta orang didunia mengalami masalah gangguan kesehatan jiwa,sepertiga diantaranya terjadi di Negara berkembang.

\section{Pembahasan}

Pelayanan kesehatan merupakan kebutuhan primer dalam kehidupan setiap manusia,dan merupakan hak untuk mendapatkannya,dalam menjaga dan meningkatkan kesehatan jiwa. Ternyata masalah kesehatan jiwa bukan hanya masalah pasien, tenaga kesehatan di rumah sakit jiwa tetapi keluarga, kelompok, masyarakat bahkan masing-masing individu. Gangguan jiwa tidak hanya berbentuk gangguan jiwa berat (kelompok psikosis) tetapi juga masalah psikososial, dan ternyata kontribusinya terhadap penyakit $f$ sik sangat tinggi. Kesehatan jiwa sangat diperlukan bagi hajat hidup orang banyak khususnya untuk keberlangsungan hidup bermasyarakat. Jiwa adalah unsur manusia yang bersifat non materi, tetapi fungsi dan manifestasinya sangat terkait pada materi. Oleh karena itu, kita dapat mempelajari dan mengembangkan kesehatan jiwa melalui fungsinya dan membuktikan kesehatan jiwa melalui manifestasinya dalam kehidupan sehari-hari. Kesehatan jiwa adalah kondisi dimana seorang individu dapat berkembang secara fisik, mental, spiritual, dan sosial sehingga individu tersebut menyadari kemampuan sendiri, dapat mengatasi tekanan, dapat bekerja secara produktif, dan mampu memberikan kontribusi untuk komunitasnya.

Kenyataanya, hasil riset kesehatan dasar Kementerian Kesehatan RI tahun 2013 
menunjukkan 0, 17\% penduduk Indonesia mengalami gangguan jiwa berat, 14, 3\% nya pernah dipasung. Selain itu $6 \%$ penduduk Indonesia mengalami gangguan mental emosional yang mengakibatkan kualitas hidup terganggu, kualitas kerja terganggu dan produktif as terganggu. Oleh karena itu diperlukan upaya peningkatan kesehatan jiwa secara komprehensif oleh semua tenaga kesehatan dengan seluruh stake holder. Upaya Kesehatan Jiwa adalah setiap kegiatan untuk mewujudkan derajat kesehatan jiwa yang optimal bagi setiap individu, keluarga, dan masyarakat dengan pendekatan promotif, preventif, kuratif, dan rehabilitatif yang diselenggarakan secara menyeluruh, terpadu, dan berkesinambungan oleh Pemerintah, Pemerintah Daerah, dan/atau Masyarakat. Kenyataannya angka terjadinya gangguan jiwa tidak pernah turun, angka kekambuhan masih tetap terjadi. Upaya lepas pasung telah dilaksanakan, namun saat ini muncul masalah baru, yaitu; kesiapan keluarga menerima pasien pasca pasung. Pasung bagi pasien gangguan jiwa telah dilepaskan, diberikan pengobatan dan perawatan di fasilitas pelayanan kesehatan jiwa. Ketika pasien sudah dinyatakan membaik, boleh dilanjutkan dengan latihan dan perawatan di rumah, keluarga yang tidak siap menerima kasien kembali. Ini adalah masalah besar bagi upaya pelatihan dan pemulihan bagi pasien gangguan jiwa. Dengan demikian, penanganan masalah gangguan jiwa bukan hanya masalah pasien, dokter, psikiater, perawat, psikolog, tenaga kesehatan lain, tetapi juga masalah keluarga, kelompok dan masyarakat. Penanganan masalah kesehatan jiwa bukan hanya urusan $f$ sik, tetapi juga urusan psikologis, sosial, spiritual dan kultutral. Keterlibatan pemerintah pusat (Kementerian Kesehatan, Kementerian Dalam Negeri, Kementerian Sosial), Pemerintah; Daerah Gubernur, Bupati, Wali Kota sampai di tingkat RT sangat diperlukan dalam mengkawal kebiajakan penanganan masalah gangguan jiwa di wilayah. Prinsipnya, upaya kesehatan jiwa adalah setiap kegiatan untuk mewujudkan derajat kesehatan jiwa yang optimal bagi setiap individu, keluarga, dan masyarakat dengan pendekatan tertentu

\section{Kesimpulan}

Pelayanan kesehatan merupakan kebutuhan primer dalam kehidupan setiap manusia,dan merupakan hak untuk mendapatkannya,dalam menjaga dan meningkatkan kesehatan jiwa. Ternyata masalah kesehatan jiwa bukan hanya masalah pasien, tenaga kesehatan di rumah sakit jiwa tetapi keluarga, kelompok, masyarakat bahkan masing-masing individu. Gangguan jiwa tidak hanya berbentuk gangguan jiwa berat tetapi juga masalah psiko-sosial, dan ternyata kontribusinya terhadap penyakit $f$ sik sangat tinggi. Kesehatan jiwa sangat diperlukan bagi hajat hidup orang banyak khususnya untuk keberlangsungan hidup bermasyarakat. Kenyataanya, hasil riset kesehatan dasar Kementerian Kesehatan RI tahun 2013 menunjukkan 0, 17\% penduduk Indonesia mengalami gangguan jiwa berat, 14, 3\% nya pernah dipasung. Selain itu $6 \%$ penduduk Indonesia mengalami gangguan mental emosional yang mengakibatkan kualitas hidup terganggu, kualitas kerja terganggu dan produktif as terganggu. Oleh karena itu diperlukan upaya peningkatan kesehatan jiwa secara komprehensif oleh semua tenaga kesehatan dengan seluruh stake holder. Ketika pasien sudah dinyatakan membaik, boleh dilanjutkan dengan latihan dan perawatan di rumah, keluarga yang tidak siap menerima kasien kembali. Ini adalah masalah besar bagi upaya pelatihan dan pemulihan bagi pasien gangguan 
jiwa. Dengan demikian, penanganan masalah gangguan jiwa bukan hanya masalah pasien, dokter, psikiater, perawat, psikolog, tenaga kesehatan lain, tetapi juga masalah keluarga, kelompok dan masyarakat

\section{Daftar Pustaka}

Riani, B. R. (2017). Hubungan Persepsi Diri, Sosial dan Keluarga Dengan Kesepian Pada Klien Skizofrenia Di Unit Pelayanan Jiwa A (UPJA) RSJ. Prof. HB. Saanin Padang (Doctoral dissertation, Universitas Andalas).

https://scholar.google.co.id/scholar?hl=id\&as_sdt=0\%2C $5 \& \mathrm{q}=$ Riani+hubungan+persepsi+diri+\%

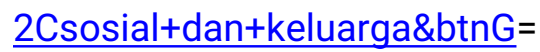

Siyoto, S., \& Sodik, M. A. (2015). Dasar metodologi penelitian. Literasi Media Publishing. https://scholar.google.co.id/scholar?hl=id\&as_sdt=0\%2C $5 \& \mathrm{q}=$ muhammad+ali+sodik\&oq=\#d=g s_qabs\&u=\%23p\%3DjGF7Wz2n5JkJ

Awan, I., \& Sodik, M. A. (2018). Diskriminasi dan Kesehatan Mental.

https://scholar.google.co.id/scholar?hl=id\&as_sdt=0\%2C5\&q=muhammad+ali+sodik+kesehata $\underline{n+m e n t a l \& b t n G=\# d=g s \_q a b s \& u=\% 23 p \% 3 D n n o s P d P l l v Q J}$

Hanifah, A. N., \& Afridah, W. (2018, November). Upaya Mengoptimalkan Pelayanan Kesehatan Jiwa Berbasis Masyarakat di Kelurahan Wonokromo Surabaya. In PROCEEDING NATIONAL SEMINAR GERMAS 2018 (Vol. 1, No. 1).

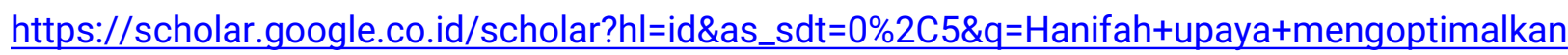
tpelayanan+kesehatan+jiwa\&btnG=\#d=gs_qabs\&u=\%23p\%3DYUKyEjlqYTUJ

Indarjo, S. (2009). Kesehatan jiwa remaja. KEMAS: Jurnal Kesehatan Masyarakat, 5(1). https://scholar.google.co.id/scholar?hl=id\&as_sdt=0\%2C5\&q=Indarjo+kesehatan+jiwa+remaja\& btnG=\#d=gs_qabs\&u=\%23p\%3DZfGBgXEgNGEJ

Yusuf, A. H. (2019). Kesehatan Jiwa; Pendekatan Holistik dalam Asuhan Keperawatan. https://scholar.google.co.id/scholar?hl=id\&as_sdt $=0 \% 2 \mathrm{C} 5 \& q=Y$ usuftkesehatan+jiwa+pendekat an+holistik\&btnG=\#d=gs_qabs\&u=\%23p\%3DrTn5sAWMO8MJ 